\title{
PRIVATIZAÇÃO DA EDUCAÇÃO NA AMÉRICA LATINA E NO CARIBE: TENDÊNCIAS E RISCOS PARA OS SISTEMAS PÚBLICOS DE ENSINO
}

\author{
Camilla Croso ${ }^{1}$ \\ Giovanna ModÉ Magalhães ${ }^{1}$
}

\begin{abstract}
RESUMO: A observação de distintas formas de privatização da educação na América Latina e no Caribe suscita indagaçóes sobre seu impacto para a realização da educação como um Direito Humano universal. Neste artigo, compartilhamos algumas expressóes do fenômeno, a partir especialmente dos dados encontrados no mapeamento Tendencias de la Privatización de la Educación en América Latina y el Caribe, realizado pela Campanha Latino-Americana pelo Direito à Educação (CLADE, 2014). A partir de análise bibliográfica e legislativa, de dados e entrevistas com ativistas da área, afirma-se o crescimento do fenômeno, a busca pelo lucro e a mercantilização da educação, fragilizando os sistemas públicos educativos, em particular as condiçóes de trabalho do docente, a gestão democrática e o financiamento público adequado.
\end{abstract}

Palavras-chave: Privatização. Direito à educação. América Latina e Caribe.

\section{PRIVATISATION IN EDUCATION IN LATIN AMERICA AND THE CARIBBEAN: TRENDS AND RISKS TO PUBLIC SCHOOL SYSTEMS}

ABSTRACT: The observation of different forms of privatization in education in Latin America and the Caribbean raises concerns about its impact in the realization of education as a universal human right. In this article, we explore some expressions of the phenomenon, particularly drawing on the report Privatization in Education trends in Latin America and the Caribbean, published by the Latin American Campaign for the Right to Education (CLADE, 2014). Considering the literature and legislative analysis, data and interviews with education activists, the growth of this phenomenon was observed, as well as that of profit making and the commodification of education, weakening public educational systems, in particular the working conditions of teachers, the democratic governance and adequate public financing.

Keywords: Privatization. The right to education. Latin America and Caribbean.

\footnotetext{
${ }^{1}$ Campanha Latino-Americana pelo Direito à Educação - São Paulo (SP), Brasil.

E-mail: camcroso@gmail.com, giovannamode@gmail.com

DOI: $10.1590 / \mathrm{ES} 0101-73302016157622$
} 


\section{Privatisation de l'Éducation en AMERiQUe Latine ET LES CARAÏBES: TENDANCES ET RISQUES POUR LES SYSTÈMES SCOLAIRES PUBLICS}

RÉSUMÉ: L'observation des différentes formes de privatisation de l'éducation en Amérique Latine et les Caraïbes soulève des questions par rapport à son impact sur la réalisation de l'éducation comme un droit humain universel. Dans cet article, nous présentons des expressions contemporaines de ce phénomène, à partir de conclusions du renseignement Tendencias de la Educación de la Privatización en América Latina y el Caribe, organisé par la Campagne Latino-américaine pour le Droit à l'Éducation (CLADE, 2014). Basé sur l'analyse bibliografique et législative, aussi bien que sur des données et des entretiens avec des militants de la région, nous avons identifié la croissance de ce phénomène, du but lucratif et de la marchandisation de l'éducation, ce qui affaiblit les systèmes éducatifs publics, avec des conséquences sur les conditions de travail des enseignants/es, la gestion démocratique et le financement public adéquat.

Mots-clés: La privatisation. Le droit à l'éducation. Amérique Latine et Caraïbes.

\section{Introdução}

A

educação é um Direito Humano fundamental, reafirmado em uma ampla gama de instrumentos no âmbito do Direito Internacional dos

Direitos Humanos, incluindo declaraçóes, convençóes, pactos e suas respectivas observaçóes gerais ${ }^{1}$, além das legislações nacionais, como é o caso de todas as Leis Gerais de Educação da América Latina (CLADE, 2015). Esse conjunto de normativas aponta também o Estado como garantidor dos Direitos Humanos, dentre eles o direito à educação, sendo responsável por respeitá-lo, protegê-lo e realizá-lo para todos e todas, sem discriminação.

O reconhecimento do Estado como responsável pelo direito à educação implica na garantia da universalização, na obrigatoriedade e na gratuidade da educação, sendo o não cumprimento dessa tríade uma violação do direito. De acordo com a normativa internacional, esse direito somente se realiza quando a educação estiver disponível e acessível, ao mesmo tempo em que for aceitável e adaptável ${ }^{2}$.

A legislação educativa em todos os âmbitos vem crescentemente ampliando o número de anos de educação obrigatória e gratuita, sendo as mais recentes conquistas o Marco de Ação da Educação 2030 (UNESCO, 2015) e os Objetivos de Desenvolvimento Sustentáveis (ONU, 2015), que estabelecem ao menos a educação primária e secundária obrigatória e gratuita, além de um ano 
de pré-primária. O Marco de Ação reconhece ainda o princípio da gratuidade estabelecido na Observação Geral 11 do Comitê dos Direitos Econômicos, Sociais e Culturais (ONU, 1999), o qual afirma que a gratuidade deve abarcar progressivamente todas as etapas educativas, inclusive a educação na primeira infância e o ensino superior.

$\mathrm{Na}$ América Latina, a gratuidade é um princípio estabelecido em todas as Leis Gerais de Educação, exceto a da Colômbia ${ }^{3}$, ainda que nesse país a Corte Constitucional tenha emitido sentença favorável ao cumprimento desse preceito, em conformidade com o Protocolo de San Salvador, do qual a Colômbia é signatária (CLADE, 2014).

O reconhecimento do Estado como responsável pelo direito implica também na existência de mecanismos de gestáo democrática e controle público sobre as políticas, de forma que a população possa participar ativamente dos processos de tomada de decisáo e monitoramento. Cabe também ao Estado implantar mecanismos de reparação de violaçóes do direito à educação e garantir o acesso a esses mecanismos - tanto os nacionais quanto outros de âmbito regional e internacional - a todos e todas.

Todo esse conjunto de implicaçóes relacionado ao papel do Estado na garantia do direito à educação conduz à centralidade do fortalecimento dos sistemas públicos de educação, além da existência de mecanismos de regulação do sistema privado, tal como também prevê a legislação internacional ${ }^{4}$. Esse fortalecimento requer como condiçóes si ne qua non, ainda que não únicas, a valorização dos sujeitos da comunidade educativa - em especial trabalhadores(as) da educação e estudantes -, a gestão democrática e um financiamento público que seja condizente com a plena garantia do direito.

A problemática da privatização, e da desvalorização do setor público que a ela se articula, aflige não apenas a regiáo da América Latina e do Caribe, mas se insere em um contexto global mais amplo. É possível observar uma crescente presença de lógicas mercantis no campo educativo, tanto no setor privado como também no setor público, fomentando verdadeiras indústrias e negócios que visam fundamentalmente à extração de lucro. Nesse contexto, observa-se a transferência de competências e de recursos públicos a terceiros privados, deslocando o papel do Estado e obstaculizando a garantia da realização do direito.

A centralidade que a extração de lucros vem crescentemente ganhando contradiz fundamentalmente a condução da educação como Direito Humano fundamental. À medida que o papel do Estado se desloca e diminui, outros atores privados e com fins lucrativos entram em cena, atuando ativamente não apenas na consolidação do setor privado, mas também dentro do próprio setor público de educação e até mesmo no campo da política pública. Esses atores são empresas de educação, fundos de investimento, instituições financeiras multilaterais, re- 
des de empresários, entre outras configuraçóes que se articulam para garantir uma crescente presença em espaços de definição das políticas educativas.

Estudos recentes sobre o que vem sendo chamando de "edunegócios" têm demonstrado como atores que visam lucro, tais como a gigante multinacional Pearson, incidem sobre o debate político educacional global, determinando as problemáticas educacionais, e geram um mercado para seus produtos e serviços como forma de solução (ROBERTSON; VERGER, 2012). Nesse sentido, de acordo com Ball e Junemann (2015, p. 7), "a realização de um propósito social está diretamente e indiretamente relacionada à procura e criação de novas oportunidades de lucro".

Preocupam também os conflitos de interesse que se instalam nas dinâmicas inerentes à privatização da educação, que tornam mais permeável a presença de atores privados no setor público (como a eleiçáo de donos de empresas educativas nos parlamentos) ou de atores públicos no setor privado (como a presença de funcionários públicos em redes de empresários pela educação).

Foi a partir deste contexto, do reconhecimento da educação como Direito Humano fundamental, do Estado como garantidor dos Direitos Humanos e da necessidade de fortalecimento dos sistemas públicos de educação na América Latina e no Caribe, que a Campanha Latino-Americana pelo Direito à Educação $(\mathrm{CLADE})^{5}$ tomou a decisão de produzir o "Mapeamento sobre as tendências da privatização da educação na América Latina e no Caribe” (2014), um amplo estudo sobre os processos de privatização da educação que vêm ocorrendo na região, elucidando seus impactos sobre a realização do direito à educação.

A preocupação da CLADE com os processos de privatização vem com a observação de indícios que apontam para a fragilização dos sistemas públicos educativos, a partir de elementos contrários às condiçôes mínimas necessárias descritas acima para seu bom funcionamento: corpo docente e estudantes desvalorizados; gestão pouco democrática; aumento da criminalização de movimentos e ativistas; e financiamento escasso.

O referido mapeamento incluiu 15 países onde a CLADE tem presença nacional ${ }^{6}$, abrange da educação infantil à secundária e conta com 3 fontes de análise: revisão das constituiçóes e legislações educativas desses países; entrevistas realizadas com ativistas e pesquisadores ${ }^{7}$; e dados e estatísticas públicas disponíveis, resultando em um conjunto de informaçóes valioso para a compreensão do fenômeno de que trataremos a seguir.

\section{Marco conceitual}

O mapeamento das tendências sobre a privatização na América Latina e no Caribe adotou como principal marco analítico a categorização desenvolvida 
por Ball e Youdell (2007), autores que apresentam duas principais formas de "privatização acobertada" que ocorrem na educação pública: a endoprivatização, ou privatização endógena, e a exoprivatização, ou privatização exógena. Identificam, além dessas, a privatização da própria política, com a consolidação de atores do setor privado influenciando cada vez mais o debate e as próprias políticas educativas, tanto em âmbito internacional como nacional.

Por privatização endógena entende-se o funcionamento de centros de ensino-aprendizagem como empresas. A introdução da lógica de mercado no âmbito das escolas públicas é, segundo Ball e Youdell (2007), a principal forma de privatização acobertada na educação pública. Essa lógica se manifesta de distintas formas, a começar pela promoção de práticas de seleção entre escolas, partindo dos resultados que estas apresentam e gerando uma competiçâo entre elas, o que supostamente elevaria a qualidade do sistema educativo como um todo, partindo da premissa de que os valores de mercado são inerentemente superiores e desejáveis, tais como competição, esforço, menor gasto e autonomia.

Além disso, a endoprivatização apresenta-se também a partir do esforço empreendido para que o setor público assemelhe-se em seu funcionamento interno ao das empresas, especialmente a partir da introdução de uma nova gestáo pública que aplica conceitos provenientes do setor privado, tais como planejamento por objetivos, supervisão de resultados e responsabilização. A implantação de mecanismos gerenciais nos sistemas de educação pública vem tendo um impacto na reestruturação da organização e da cultura dos serviços públicos, em especial nas relaçóes estabelecidas entre os sujeitos da comunidade educativa, subjugando o corpo docente e estudantil a lógicas de individualização, competição e ranqueamento.

Importante ressaltar especialmente a questáo da gestáo por resultados e responsabilização, que afeta diretamente o professorado. É cada vez mais comum que os salários sejam determinados em função de resultados obtidos em provas estandardizadas, ainda que estes muitas vezes sejam determinados por fatores exógenos ao âmbito educativo e fujam da alçada do ensino em si. A gestáo por resultados e a responsabilização têm impacto na valorização da profissão docente, em suas condiçóes de trabalho e autonomia pedagógica, acarretando inclusive na fragilização da negociação sindical coletiva (BALL; YOUDELL, 2007).

A segunda categoria de privatização na educação pública é a privatização exógena, ou seja, a incorporaçáo do setor privado nos centros públicos de educação. Ainda que a presença do setor privado na oferta educacional em diversos países do mundo venha de longa data, é recente a possibilidade de que o setor público de educação se converta em fonte de lucro privado. Esse fenômeno pode ser observado de distintas maneiras, na medida em que os governos passam a comprar da iniciativa privada não apenas materiais didáticos, mas também a elaboração de currículos, a formação e o treinamento do corpo docente, o desenvolvimento, a aplicação e o processamento de provas e avaliaçóes estandardizadas ou até mesmo "pacotes" 
completos que contemplem todos esses elementos. Vale ressaltar especialmente a atuação de empresas anglo-saxônicas, em âmbito internacional, como é o caso da Pearson, GEMS (com sede em Dubai), Phoenix, Cambridge Education, Kaplan, New Zealand Educated, entre muitas outras (BALL; YOUDELL, 2007).

Além disso, é possível observar a subcontratação de serviços educativos considerados "não básicos", tais como o transporte escolar, a merenda e a limpeza. Mais recentemente, esses serviços também incluem a manutenção de equipamentos informáticos e serviços de assistência técnica e apoio geral, como a contratação de recursos humanos e a supervisão por resultados.

Também vale ressaltar a subcontratação de centros de ensino, onde escolas públicas individuais ou redes de ensino são transferidas ao setor privado para que as dirijam, podendo inclusive permitir o lucro. Neste modelo, conhecido como escolas "charter", a premissa é de que os provedores privados são essencialmente mais capazes de prestar serviços educativos de qualidade e são apresentados como alternativa e resposta aos problemas ditos inerentes do Estado. Nesse âmbito, observa-se também a oferta da educação do setor privado com subvenção pública, como ocorre com escolas de financiamento compartilhado. Ressaltamos também a promoção de "vouchers", ou subvençóes públicas à demanda, entregues às famílias para que possam escolher a escola desejada na rede privada.

Além da privatização endógena e exógena da educação pública, o mapeamento realizado pela CLADE também considerou o que Ball e Youdell (2007) chamam de privatização da política, e que no estudo em discussão nomeou-se de governança corporativa. Esse conceito refere-se à participação direta ou indireta de representantes do setor privado e da indústria da educação na definição do debate e da agenda pública educativa em todos os âmbitos. Essa influência é derivada da criação de redes de relações sociais entre políticos, funcionários públicos e empresários. De maneira geral, existe uma permeabilidade e uma movimentação de mão dupla de pessoal entre o Estado e os serviços públicos, por um lado, e do setor privado por outro, sendo inclusive possível a ocupação simultânea de cargos públicos e privados, o que constitui um grave potencial de conflito de interesses e gestão em causa própria. Ball e Youdell (2007) ressaltam que essa forma de privatização, tal como as outras duas apresentadas, tende também a ser acobertada, passando muitas vezes desapercebida.

\section{Mapeando as principais características da privatização da educação pública na América Latina e no Caribe}

\section{Um olhar sobre as leis}

A partir do processo de coleta de dados descrito, elencaremos a seguir alguns elementos encontrados que nos parecem relevantes para a compreensáo do 
panorama contemporâneo dos processos de privatização da educação na América Latina e no Caribe. Seguindo o marco conceitual delineado, comentaremos primeiramente o que foi observado em termos normativos, para, em seguida, tratar das práticas destacadas no que diz respeito à privatização exógena, à endógena e também à chamada governança corporativa.

Um primeiro eixo analítico, portanto, relaciona-se ao conjunto legislativo da regiấo, tanto os capítulos de educação das Constituiçóes Nacionais dos países envolvidos como suas Leis Gerais de Educação, indagando se existiriam, nas normativas vigentes, incentivos ou impeditivos de privatização da educação, além de formas de regulamentação dos mecanismos relacionados com a privatização de e na educação. A partir do conjunto, pode-se afirmar que todos os países analisados contam com leis que de alguma maneira facultam ao Estado transferir competências relativas à oferta da educação pública para o setor privado. Algumas normas, como veremos, alentam tal participação, inclusive com fins lucrativos, seja oferecendo serviços, seja participando do debate político educativo.

Guardadas as especificidades de cada um deles, foram identificados três grupos de países. Em um primeiro grupo, formado por Argentina, Bolívia, Brasil, Colômbia, Equador, México e República Dominicana, estáo aqueles que, sim, permitem mecanismos de concessão de escolas públicas para a iniciativa privada, compra de vagas no setor privado, ou a transferência de subsídios públicos para a educação particular, mas sempre estabelecendo critérios para tal acordo. Um exemplo desses critérios é a proibição de que tais instituiçôes privadas tenham fins de lucro. Outro é que devem estar localizadas em zonas onde o Estado tem pouco alcance. A título ilustrativo, podemos mencionar o caso da Constituição brasileira, que estabelece em seu artigo 213:

Os recursos públicos serão destinados às escolas públicas, podendo ser dirigidos a escolas comunitárias, confessionais ou filantrópicas, definidas em lei, que:

I - comprovem finalidade não-lucrativa e apliquem seus excedentes financeiros em educação;

II - assegurem a destinação de seu patrimônio a outra escola comunitária, filantrópica ou confessional, ou ao Poder Público, no caso de encerramento de suas atividades. (CF/88, Art.213, Inc. I e II)

Outro exemplo pode ser encontrado no caso argentino, com a Lei de Educação Nacional (LEN, 2006), que em seu artigo 13 esclarece que o Estado reconhece, autoriza e supervisiona o funcionamento de instituiçóes educativas não estatais de gestão privada, confessionais ou não confessionais, de gestão cooperativa e de gestão social. No artigo 65, indica os critérios necessários para tal mecanismo: 
La asignación de aportes financieros por parte del Estado destinados a los salarios docentes de los establecimientos de gestión privada reconocidos y autorizados por las autoridades jurisdiccionales competentes, estará basada en criterios objetivos de justicia social, teniendo en cuenta la función social que cumple en su zona de influencia, el tipo de establecimiento, el proyecto educativo o propuesta experimental y el arancel que se establezca.

(LEN, Art.65)

Ainda com relação ao caso argentino, importante notar que foi o único país onde se encontrou restrição legal à participação do setor privado estrangeiro no campo educativo. A LEN de 2006 restringe os tratados multilaterais que alentam a mercantilização da educação pública. Não foi constatado nada nesses termos nos demais casos.

Já um segundo conjunto de países, composto apenas por Nicarágua e Costa Rica, engloba aqueles onde, ao menos no âmbito legal, tais critérios parecem não estabelecidos. Na Nicarágua, por exemplo, as instituições de ensino não governamentais são classificadas em duas categorias: centros educativos privados e centros educativos subvencionados. Os segundos, de acordo com a Lei Geral de Educação de 2006, são justamente os colégios privados que recebem fundos públicos para o pagamento de docentes e pessoal administrativo. Náo foram encontrados critérios para tais transferências de recursos, restando a pergunta se os mesmos podem ou não ter fins de lucro. Essa mesma lei menciona a relevância de que representantes de empresas participem da definição das políticas educativas. Por sua vez, a Constituição da Costa Rica, datada de 1949, resolve em seu art. 80 que o Estado "estimulará a iniciativa privada na educação".

Por fim, um terceiro grupo de países inclui os casos mais extremos, em que a legislação não apenas permite mas também alenta ao setor privado a aumentar sua participação na oferta educativa, e para isso prevê a transferência de recursos públicos. Essa construção foi observada nas normativas do Chile, da Guatemala, de Honduras, do Paraguai e do Peru. O caso chileno é paradigmático, já que a Lei Geral de Educação (LOE, 2009) ${ }^{8}$ define o financiamento compartilhado do sistema educativo:

El sistema de educación será de naturaleza mixta, incluyendo una de propiedad y administración del Estado o sus órganos, y otra particular, sea ésta subvencionada o pagada, asegurándole a los padres y apoderados la libertad de elegir el establecimiento educativo para sus hijos (LOE, 2009, Art.4).

Já a Constituição do Peru expressa uma posição ainda mais forte em relação ao papel do setor privado na oferta educativa e na transferência dos recursos públicos: 
Con el fin de garantizar la mayor pluralidad de la oferta educativa, y en favor de quienes no puedan sufragar su educación, la ley fija el modo de subvencionar la educación privada en cualquiera de sus modalidades, incluyendo la comunal y la cooperativa. (CONSTITUIÇÃO, 1993, Art. 17)

Interessante perceber, além disso, que o Art. 24 da Lei Geral de Educação peruana institui as empresas como contribuintes do desenvolvimento da educação nacional:

Las empresas, como parte de la sociedad, contribuyen al desarrollo de la educación nacional. Les corresponde: participar en el diseño de politicas educativas, contribuyendo a identificar las demandas del mercado laboral y la relación de la educación con el desarrollo económico productivo del país (...). (LGE, Art. 24, ítem a)

\section{Um olhar sobre as políticas e práticas}

Para além das possibilidades normativas observadas, o conjunto de dados mostrou a vigência e o crescimento de diferentes políticas e práticas de privatização da educação nos países analisados. Ainda que se apresentem em arranjos institucionais bastante diversos, a depender do país, pode-se encontrar semelhanças e tendências comuns entre vários deles, de maneira a somar mais elementos para a compreensão do panorama regional.

Nota-se, em primeiro lugar, a nitidez do que chamamos de formas de privatizaçáo exógenas, as que vêm expressas em distintas modalidades de transferência de recursos públicos para o sector privado, inclusive a transferência da gestão completa das escolas públicas a entidades privadas, fenômeno conhecido em alguns países como "concessão de escolas públicas".

Em seis países (Argentina, Brasil, Chile, Colômbia, Equador e Honduras), foram observados casos de fundações (vinculadas ou não a grupos empresariais) e organizaçóes religiosas que, em geral, estabelecem convênios com o Estado e, com isso, passam a ter algum grau de participação na gestâo pública. Já em quatro países relatou-se o fenômeno da transferência completa da gestáo para as organizaçôes privadas (Argentina, Brasil, Colômbia e Honduras).

Um caso paradigmático são os chamados Colégios em Concessão na Colômbia, modalidade de aliança público-privada que tem início ao final dos anos 1990 com a proposta de "promover a eficiência da gestão escolar e a melhoria da qualidade educativa". Atualmente, são 70 no país, sendo 25 deles na capital. No entanto, Termes et al. (2015) demonstram, por meio de 
estudo em Bogotá, que a proliferação de tais colégios gerou segregação ao interior do sistema educativo e uma notável piora nas condiçóes de trabalho do docente. De acordo com a pesquisa, a promessa da qualidade tampouco se confirma, ainda que partam de uma grande vantagem comparativa com relação às escolas públicas tradicionais: têm melhor infraestrutura, menor proporção de estudantes por professor e ensino em jornada completa. Vantagens essas, importante ressaltar, promovidas com recursos públicos e que terminam por reforçar na população a já disseminada crença de que o sector privado é inerentemente melhor.

Diante da observação do fenômeno em seus países, os(as) ativistas entrevistados(as) da Argentina, do Brasil, da Colômbia e do Equador apresentaram sérias críticas a esse modelo e seu impacto no sistema educativo, em particular ressaltaram a desqualificação do serviço público, a perda da autonomia dos estabelecimentos, a ausência do controle pedagógico e financeiro dos estabelecimentos, além da má utilização dos recursos. A título de exemplo, ilustramos com os depoimentos das organizaçóes da Argentina e do Equador:

El argumento por el que se sostiene y amplía la estructura del sistema de subsidios privados tiene que ver con el menor costo por estudiante. El sistema privado genera cierta diversidad en la calidad de la educación argentina, reduciéndose significativamente la calidad del sistema público. Según informes producidos, en el sistema de subsidios predomina la opacidad y la discrecionalidad politica en el proceso de asignación de los aportes. No se establecen en la normativa claros criterios para el monto global anual de subsidios ni su distribución entre las y los solicitantes. (Ativista Argentina, CLADE, 2014)

Los procesos de matriculación se configuran en procesos de exclusión precisamente de aquellos sectores que menos recursos y oportunidades han tenido. (Ativista Equador, CLADE, 2014)

Outra modalidade também observada no âmbito da privatização exógena foi o que chamamos de subvenção pública à demanda, traduzida em particular na compra de vagas nas escolas privadas por meio de fundos públicos. Tal mecanismo foi encontrado no Brasil, na Colômbia e no Chile. No caso brasileiro, foi reportado o subsídio público para matrículas no sistema privado na educação infantil e no ensino superior. Já no contexto chileno foram relatadas diversas formas de subvenção aos estudantes, como a transferência per capita, o aporte para construção de escolas e as subvençóes específicas para estudantes em situação de vulnerabilidade social.

Observou-se, finalmente, a compra de serviços privados pelo setor público envolvendo grandes grupos empresariais. O conjunto de produtos adquiridos 
pelos diferentes níveis de governo inclui materiais educativos (de livros didáticos a notebooks), a formação de docentes e outros profissionais - estes mais mencionados - além de tecnologias educativas e de gestão, serviços de transporte, equipes de laboratório, uniformes, merenda escolar, entre outros. $\mathrm{Na}$ Guatemala, na Argentina, em Honduras, no Brasil, na Bolívia, na Colômbia, no Chile e no México, observou-se o crescimento dessa modalidade.

No Brasil, como demonstram Adriáo et al. (2015), uma das vertentes a serem observadas é a venda de sistemas privados de ensino para as redes públicas municipais, desenvolvendo um mercado pelo qual competem as mais conhecidas multinacionais do ensino. Os recursos para a compra de tais pacotes variam, mas em todo caso deixam de ser aplicados no fortalecimento de aspectos básicos da educação pública.

Os efeitos de tais mecanismos foram igualmente mencionados nas entrevistas com ativistas, e vão desde a desregulamentação do sistema educativo até a proliferação de grupos que se aproveitam dos recursos públicos exercendo influências e forte pressão para que tais contratos perpetuem-se. O caso da Colômbia é particularmente grave, mostrando um extremo de funcionários que ousaram inverter essa prática privatista em algumas localidades e receberam ameaças à sua vida:

Se han creado circuitos de corrupción que impiden que los contratos de compra de cupos con estos colegios se terminen. En casos como el de Cartagena o Bogotá, las y los funcionariaslos que han intentado revertir esta práctica privatista, han recibido amenazas contra su vida. (Ativista, Colombia, CLADE, 2014)

Ainda com relação às políticas e práticas vigentes, tratamos de observar as formas de privatização endógenas presentes no conjunto de países analisados. Assim, os dados confirmaram a existência do fenômeno e elencam distintas formas com que este se expressa, em particular nos seguintes países: Argentina, Brasil, Chile, Colômbia, Equador, Honduras, México e Peru.

A vigência do modelo de gestão por resultados foi uma das formas mais evidentes dessa categoria de privatização. No caso chileno, por exemplo, as entrevistas destacaram a pressão das escolas para o alcance de bons resultados nas provas estandardizadas, alimentando a construçáo de rankings que, por sua vez, determinarão a distribuição de recursos e a seleção de estudantes. $\mathrm{O}$ mesmo ocorre em Honduras, embora em menor escala. Já no Brasil, a entrevista releva o papel das alianças público-privadas na instalação e disseminação de lógicas competitivas no interior do sistema público. $\mathrm{Na}$ Colômbia, termina-se por gerar uma lógica que transforma diretores(as) das escolas em gerentes interessados essencialmente no número de estudantes atendidos, o que, consequentemente, gera maior quantidade de recursos públicos. 
Um aspecto específico da gestão por resultados foi observado nas condições impostas à carreira docente. Assim, encontramos que muitas vezes a manutenção do contrato com o(a) docente ou sua remuneração depende diretamente de seu desempenho em avaliaçóes, como ilustra a entrevista com a organização do Equador:

La evaluación a docentes y el ingreso de nuevas/os docentes se miden a través de pruebas estandarizadas; sin embargo no se han mejorado sustancialmente los procesos de formación inicial y capacitación docente. (Ativista, Equador, CLADE, 2014)

No caso da Colômbia, observou-se, nos já mencionados colégios públicos de concessão, que os contratos com docentes e sua remuneração dependem diretamente de avaliaçóes de desempenho. Característica semelhante foi encontrada no México, mas nesse caso para todo o sistema público. De acordo com o relato obtido, a carreira docente consiste em um:

Sistema de estímulos económicos vinculado a los exámenes de estudiantes y maestras/os con un escalafón de cinco niveles con un promedio de 12 años para llegar al nivel más alto. (Ativista, México, CLADE, 2014)

Quanto à valoração de tais práticas, as entrevistas dos(as) ativistas expressaram duras críticas em particular sobre a gestão por resultados para docentes e as condiçóes de trabalho associadas a esta lógica. Foram mencionados a degradação e o empobrecimento do ensino, bem como o desenvolvimento de condutas individualistas, assim como a corrupção e a naturalização de uma lógica competitiva com base no prêmio e castigo.

A análise dos dados permite também destacar a emergência e consolidação de novas formas de privatização da educação nas últimas décadas, estando entre elas a notável ascensão do que chamamos de governança corporativa. Nesse quesito, a principal forma observada foi a presença de redes de empresários em 14 países da região ${ }^{9}$, compostas, em geral, por fundações empresariais, bancos e indivíduos.

A pergunta central, diante da constatação da entrada de tais atores no debate público educativo, é sobre a agenda desses grupos de empresários para a educação pública, tema que certamente merece maior aprofundamento em pesquisas futuras. $\mathrm{O}$ mapeamento trouxe algumas pistas, em particular nas entrevistas com ativistas da sociedade civil. O exemplo do México é bastante ilustrativo, quando a entrevista afirma que a coalizão de empresários desse país termina por dar descrédito à educação pública e aos seus docentes, em particular a partir das reformas pelas quais passou o sistema educativo a partir de 2013: 
Se ha creado una triple alianza de tecnócratas, empresarios y politicos que deciden por la calidad de la educación como bandera politica para transformar el pais solucionando las deficiencias pedagógicas para adaptarlas a los retos del siglo XXI (...) En nombre de la "calidad" se establece una contra reforma encaminada a dejar de lado la estabilidad laboral, y reducir la calidad al aprovechamiento académico, dejando el peso en evaluar a las y los profesores y no al Sistema de Educación en su conjunto; la evaluación no se plantea como un instrumento para detectar problemas, deficiencias, retos o aciertos, sino para convertirse en un mecanismo de control y vigilancia sobre maestros y alumnos. (Ativista, México, CLADE 2014)

De maneira semelhante, ao analisar o movimento "Todos Pela Educaçáo" no Brasil, Martins (2013) afirma que, ao inserir-se na arena de disputas políticas do país, o grupo reconfigura o espaço público e conjuga as demandas e propostas para educação provenientes do governo, iniciativa privada e outros setores da sociedade. Além disso, destaca seu maciço poder de comunicação, com um respaldo técnico que sustenta suas afirmações e propostas e com um alto grau de articulação com o Estado.

Esse aspecto da comunicação como estratégia central parece ser comum à maioria das redes de empresários analisadas, uma vez que entre seus membros constata-se, em geral, a presença dos meios de comunicação hegemônicos do país, outro tema que amerita aprofundamento em pesquisas futuras. De todo modo, os grandes grupos de comunicação são parte importante das articulaçóes empresariais que têm a educação entre seus negócios e progressivamente começam também a operar na definição de políticas educativas.

Faz-se necessário, portanto, entender que discursos estão disseminando acerca da educaçáo pública e de que maneira corroboram o fenômeno da privatização. Ao analisar a cobertura sobre privatização da educação dos principais meios hegemônicos da região, Porta (2015) afirma a predominância de fontes ligadas a consultores de empresas privadas, que terminam por manifestar visóes de desqualificação da educação pública e suas lutas. Em geral, expressam a visão de uma iniciativa privada mais eficiente ante as deficiências das escolas públicas e dos funcionários estatais. Destacam notícias que desqualificam as greves de professores, associando-as a delitos, enquanto, ao mesmo tempo, abundam informaçóes sobre as vantagens que determinadas empresas levam às escolas, oferecendo tecnologia e produtos de ponta.

Verificou-se, por outro lado, que o modelo das redes de empresários extrapola, na América Latina e no Caribe, as fronteiras nacionais. No ano de 2011, surge a Rede Latino-americana de Organizaçóes da Sociedade Civil para a Educação, que ainda que se autodenomine como de organizaçóes da sociedade civil de maneira geral, reúne as coalizões predominantemente de empresários em 14 países da regiáo, iniciativa igualmente importante de constar na agenda de pesquisas futuras sobre a temática deste artigo. 
Internacionalmente, nota-se, de maneira análoga, o surgimento da Global Business Coalition for Education, que reúne empresas multinacionais com o objetivo de participar do debate e das decisóes globais no que diz respeito à educação. Em seus documentos de apresentaçáa ${ }^{10}$, a rede afirma que "une o setor privado para acelerar o progresso na oferta de educaçáo de qualidade para todas as crianças e jovens do mundo", já que "educação é chave para expandir oportunidades de emprego futuro". Alenta as empresas a investirem na educação, em um paradigma claramente de formação de capital humano: "Para as empresas, investir em educação promove crescimento econômico, sociedades estáveis, comunidades saudáveis e facilita a existência de negócios”.

Por fim, notou-se o crescimento de gigantes internacionais do edunegócio na América Latina e no Caribe, que se instalam como atores políticos influentes, tal como a Pearson, multinacional presente em 19 países da região, em particular nos mercados de venda de livros, educação a distância, certificação, avaliações educativas, aplicação da prova Programa Internacional de Avaliação de Alunos (PISA, por sua sigla em inglês), consultorias, entre outros. Será fundamental acompanhar sua atuação na regiâo, já que, internacionalmente, nota-se seu papel na promoção de cadeias de escolas privadas de baixo custo, caracterizadas por oferecer à população de baixa renda uma educação de má qualidade, fundamentando-se na existência anterior de uma profissão docente que sofreu precarização e em particular com sindicatos também fragilizados (BALL; JUNEMANN, 2015). Ao mesmo tempo, a Pearson ocupa globalmente espaços estratégicos de tomada de decisóes na política internacional, como, por exemplo, integrando o Comitê Diretivo da Aliança Global pela Educação ${ }^{11}$.

\section{Considerações finais}

Ainda que o contexto latino-americano conte com movimentos sociais e de Direitos Humanos estabelecidos e tenha tido, por um período de tempo e em alguns países da regiáo, governos que questionaram a primazia do mercado na definição das políticas, o fenômeno da privatização da educação está presente e se manifesta em todas as suas formas. Isso vem se evidenciando a partir de mecanismos legais e políticos a partir dos quais se transferem recursos e responsabilidades do setor público ao privado e particularmente na intensificação da incidência do setor privado no debate e na definição da agenda pública educacional.

A presença da privatização endógena e exógena da educação pública na América Latina e no Caribe vem fragilizando os sistemas públicos de educação, especialmente no que tange ao desempoderamento dos sujeitos educativos e sua individualizaçáo, bem como o enfraquecimento da gestáo democrática e a perda de recursos públicos para a educação pública. A construção de imaginários que buscam naturalizar a ideia de que o setor privado é inerentemente superior e mais 
confiável que o setor público é um importante elemento para engendrar a promoção das diferentes formas de privatização.

Por outro lado, a fragilização dos sistemas públicos de educação propicia um ambiente favorável para a implantação e o crescimento de escolas privadas de baixo custo de má qualidade, como nicho de mercado voltado aos setores de baixa renda da população, segmentando e fraturando ainda mais o tecido social e constituindo, assim, um círculo vicioso que demonstra a incompatibilidade da motivação do lucro na educação com a perspectiva da educação como Direito Humano fundamental.

A privatização da educação não apenas fragiliza os sistemas públicos de educação, mas também coloca em xeque o caráter público da educação, bem como preceitos democráticos, na medida em que disputa seus sentidos e propósitos e transfere ao setor privado elementos essenciais da prática educativa, como o desenvolvimento de conteúdos, das avaliaçóes e da orientação da prática docente, sem que haja debate público e participação social. A progressiva influência que vêm conseguindo as grandes corporaçóes e redes empresariais, capazes de mover um grande poder econômico, político e simbólico, promove fortes assimetrias no processo democrático de definição da política pública.

É fundamental que os sistemas públicos de educação possam ser fortalecidos, resgatando preceitos democráticos, bem como o sentido público da educação e a concepção da educação como Direito Humano fundamental. A educação é, em si mesma, um espaço privilegiado de formação de sujeitos capazes de promover essas mudanças, mas, para isso, os próprios sistemas educativos devem ser promotores de democracia, igualdade e cidadania.

\section{Notas}

1. O Direito Humano à educação foi afirmado e seu conteúdo expandido em diferentes instrumentos: Declaração Universal dos Direitos Humanos (1948), Pacto Internacional de Direitos Econômicos, Sociais e Culturais (1966), Convenção dos Direitos da Criança (1989), Observaçôes Gerais 11 e 13 do Comitê DESC (1999), Protocolo de San Salvador do Sistema Interamericano de Direitos Humanos (1988), entre outros.

2. Relação à flexibilidade capaz de responder às necessidades dos estudantes, nos mais diferentes contextos sociais e culturais.

3. No artigo 183 dessa norma são habilitados alguns tipos de cobrança na educação estatal.

4. Observaçôes Gerais 5 e 16 do Comitê dos Direitos da Criança.

5. A CLADE é uma rede de organizaçóes da sociedade civil presente em 16 países da América Latina e do Caribe que tem como missáo defender o Direito Humano a uma educação transformadora pública, laica e gratuita para todas e todos, durante toda a vida e como responsabilidade do Estado. Disponível em: <http://www.campanaderechoeducacion.org/v2/pt/a-campanha/missao.html>. Acesso: em 9 de dez. de 2015 . 
6. Argentina, Bolívia, Brasil, Chile, Colômbia, Costa Rica, Equador, Guatemala, Honduras, Paraguai, Peru, República Dominicana, México, Nicarágua e Haiti.

7. O Mapeamento contou com entrevistas de 16 ativistas selecionados por serem representantes de organizaçôes membros da CLADE, que atuam a favor do Direito Humano à educação em seus países e acompanham a política educativa cotidianamente.

8. Em maio de 2014, a presidenta Michelle Bachelet assinou projetos de lei que modificariam a LOE, propondo o fim do lucro na educação, da seleção de estudantes e estabelecendo a plena gratuidade na educação primária. As propostas seguiam em debate e tramitação.

9. Argentina, Brasil, Chile, Colômbia, El Salvador, Equador, Guatemala, Honduras, México, Nicarágua, Panamá, Paraguai, Peru e República Dominicana.

10. Disponível em: <http://gbc-education.org/about-us>. Acesso em: 9 dez. 2015.

11.Disponível em: <http://www.globalpartnership.org/board-of-directors>. Acesso em: 9 dez. 2015.

\section{Referências}

ADRIÃO, T.; GARCIA, T.; BORGHI, R.; BERTAGNA, R.; PAIVA, G.; XIMENES, S. Sistemas de Ensino Privado na Educaçáo Pública Brasileira: consequências da mercantilização para o direito à educação. Relatório de Pesquisa. GREPPE, Ação Educativa. 2015.

BALL, S.; YODELL, D. Privatización encubierta en la educación pública, Internacional de la Educación. Bruselas, 2007. Disponível em: <http://www.joanmayans.com/privatizacion encubierta de la educacion publica.pdf >. Acesso em: 9 de dez. de 2015.

BALL, S.; JUNEMANN, C. Pearson and Palf: The Mutanting Giant. Bruxelas: Education International, 2015. Disponível em: <http:/www.ei-ie-al.org/mercantilizacion/ Mercantilizaci\%C3\%B3n\%20educativa-\%20art\%C3\%ADculos, \%20publicaciones/ Ingl $\%$ C $3 \%$ A 9 s/Junemann $\% 20 \mathrm{C} \% 20$ and $\% 20$ Ball $\% 20$ S. $\% 20 \% 282015 \% 29 \% 20$ Pearson\%20and\%20PALF,\%20The\%20Mutating\%20Giant.\%20pdf.pdf>. Acesso em: 9 dez. 2015.

CAMPANHA LATINO-AMERICANA PELO DIREITO À EDUCAÇÃO (CLADE). Mapeo sobre Tendencias de la Privatización de la Educación en América Latina y el Caribe. São Paulo: CLADE, 2014.

Las Leyes Generales de Educación en América Latina - el derecho como proyecto político. São Paulo: CLADE, 2015.

- Consulta sobre la Gratuidad de la Educación Básica: aportes a partir de estudios de caso en Colombia, Guatemala, Honduras y Paraguay. São Paulo: CLADE, 2014.

MARTINS, E.M. Movimento "todos pela educação": um projeto de nação para a educação brasileira. 2013. Dissertação (mestrado). Faculdade de Educação. Universidade Estadual de Campinas, Campinas.

ORGANIZAÇÃO DAS NAÇÓES UNIDAS (ONU). Objetivos de Desenvolvimento Sustentável. Nova York: ONU, 2015. 
Observación General 11 del Comité de Derechos Económicos, Culturales y Sociales. Ginebra: ONU, 1999.

Observación General 13 del Comité de Derechos Económicos, Culturales y Sociales Ginebra: ONU, 1999.

PORTA, E. En la prensa hegemónica, la educación aparece vinculada a la escuela pública como caos y a la escuela privada como calidad. Entrevista ao portal Contracorriente. Disponível em: $\quad<$ http://www.campanaderechoeducacion.org/privatizacion/entrevista-en-la-prensahegemonica-la-educacion-aparece-vinculada-a-la-escuela-publica-como-caos-y-a-la-escuelaprivada-como-calidad/>. Acesso em: 9 dez. 2015.

SINGH, K. Report of the Special Rapporteur on the right to education. Disponível em: $<$ http://ap.ohchr.org/documents/dpage e.aspx?si=A/69/402 >. Acesso em: 9 dez. 2015.

ROBERTSON, S.; VERGER, A. A origem das parcerias público-privada na governança global da educação. Educação \& Sociedade, v. 33, n. 121, p. 1133-1156, 2012.

TERMES, A.; BONAL, X.; VERGER, A.; ZANCAJO, A. Alianzas Público-Privadas en la educación colombiana: las implicaciones en equidad y calidad de los Colegios en Concesión de Bogotá. Iniciativa de Investigación sobre la Privatización en la Educación (PERI-OSF), n. 66, 2015.

TOMASEVSKI, K. Human Rights Obligations in Education: the 4-A Scheme. Wolf, Nijmegen, 2006.

ORGANIZAÇÃO DAS NAÇÕES UNIDAS PARA EDUCAÇÃO E CULTURA (UNESCO). Educación 2030: Declaración de Incheon y Marco de Acción - Hacia una educación inclusiva y equitativa de calidad y un aprendizaje a lo largo de la vida para todos. Incheon: UNESCO, 2015.

Recebido em 11 de dezembro de 2015.

Aprovado em 29 de janeiro de 2016. 